\title{
Globalización y mundo jurídico
}

\section{Antonio Garrigues Walker}

Abogado por la Universidad Complutense de Madrid.

SUMARIO:

I. Introducción.

II. La resistencia a las instituciones globales.

III. Conclusión. 


\section{INTRODUCCIÓN}

La crisis que estamos viviendo ha puesto de manifiesto - además de la "insoportable levedad del ser" - los enormes déficits jurídicos y democráticos de una imparable globalización que, en términos objetivos, no puede calificarse como civilizada. Es esta una ocasión histórica perfecta para asumir que no podemos seguir avanzando sin instituciones que tengan la condición de ser globales, independientes y eficaces, unos calificativos que eliminan de esta categoría a las organizaciones internacionales que operan actualmente en el mundo, exceptuando, solamente, y con muchas reservas, a algunas organizaciones que tienen objetivos, exclusivamente, técnicos o científicos.

\section{LA RESISTENCIA A LAS INSTITUCIONES GLOBALES}

La resistencia a las instituciones globales tiene un largo recorrido histórico y en la época moderna se atribuye fundamentalmente $-y$ con buenas razones - a los Estados Unidos. Es una resistencia que se manifiesta, según el momento y las circunstancias, con mayor o menor intensidad pero que siempre está ahí. Tiene que ver con sentimientos de superioridad y con sentimientos de autosuficiencia, ambos razonablemente justificados; con ignorancias, a veces profundas, de lo que es el resto del mundo; con un convencimiento pleno de que son el mejor líder posible; y sobre todo con la inaceptabilidad absoluta de que su seguridad y sus intereses puedan depender, aún mínimamente, de otros. Francis Fukuyama, que ha estudiado a fondo este tema, lo explica diciendo que: "para la mayoría de los norteamericanos no existe otra fuente de legitimidad democrática para tomar decisiones que la de su propio estado-nación".

Durante la Presidencia de Bush, las tendencias americanas tradicionales al aislacionismo y al unilateralismo alcanzaron niveles verdaderamente inquietantes y se reforzaron especialmente, después del $11 / \mathrm{S}$ que sensibilizó -y sigue sensibilizando- a la ciudadanía norteamericana con una intensidad que los europeos nunca hemos valorado y seguimos sin valorar adecuadamente. Esta sensibilidad, justificó la absolutamente injustificable cárcel de Guantánamo que fue construida en un asentamiento de 113 kilómetros cuadrados que los EE.UU. alquilaron a Cuba en 1903, por 4000 dólares anuales y que en la actualidad, tenía un coste operativo de 100 millones de dólares. Allí siguen hasta el momento más de 400 prisioneros de 40 países distintos, a los que calificándolos de "combatientes enemigos", no se les concede ninguno de los derechos de los prisioneros de guerra utilizando interpretaciones y argumentos jurídicos de nula consistencia. Es un caso extremo de limbo o vacío legal abusivo frente al cual la reacción crítica de la sociedad americana - que es una sociedad con buenos reflejos éticos - ha sido sorprendentemente bajo.

Otro caso. Estados Unidos sigue, hasta el momento, manteniendo su oposición frontal a aceptar el protocolo de Kyoto. Bill Clinton, firmó en su día este Protocolo pero, nada más alcanzar el poder, el Presidente Bush anunció que su gobierno ni siquiera lo enviaría al Senado. El principal negociador americano, Harlan Watson, lo dejó bien claro:"Ios Estados Unidos no ratificarán el Protocolo ni hoy, ni mañana, ni nunca, porque eso significaría reducir un $35 \%$ el crecimiento industrial de nuestro país", un argumento que elaboraron y supieron vender al Presidente Bush, importantes empresarios americanos. A lo anterior hay que añadir que, en términos de emisión de gases nocivos, Norteamérica es el líder absoluto con un $20 \%$, seguido de Europa con un 10\% y de China que, por el momento, no llega a un 3\%.

Un ejemplo final, - aunque hay otros- del rechazo a cualquier tipo de acuerdo multilateral por parte de la administración Bush fue el hecho, sin precedentes diplomáticos, de "desfirmar" ("unsign") el acuerdo que establecía la Corte Penal Internacional. La retirada de la firma del Presidente Clinton del acuerdo se acompañó con una negociación bilateral con gobiernos de todo el mundo para firmar acuerdos de impunidad. Mediante estos acuerdos, los gobiernos se comprometen a no entregar ni trasladar a ciudadanos estadounidenses acusados de genocidio o crímenes de guerra ante la Corte Penal Internacional. 
Dicho todo lo anterior, hay que hacer con urgencia una aclaración importante. La resistencia a las instituciones globales y las tendencias al unilateralismo no son en modo alguno patrimonio exclusivo de los EEUU. A lo largo de la historia, todos los países que han acumulado poder, más o menos hegemónico, - y entre ellos, Españahan actuado de forma similar, $y$, en muchos casos, aún más negativa. En el tiempo actual, el resto de los países occidentales, y desde luego, Rusia y China (que tampoco han ratificado el tratado de la Corte Penal Internacional) participan de forma inequívoca en estas actitudes y lo hacen, como es natural, en proporción a su cuota de poder y a su capacidad de acción y de influencia. La incapacidad europea para avanzar mínimamente en el proceso de unidad política es otro triste y doloroso ejemplo dentro de esta misma tendencia. Hay que decir finalmente que los EEUU vienen asumiendo, en cuanto a gobernanza y responsabilidad mundiales, tanto política como económicamente, un porcentaje muy superior al que le corresponde y eso se está demostrando de manera muy especial en la búsqueda de soluciones en la actual crisis financiera, una crisis de la que son en gran medida culpables y al mismo tiempo el único país capaz de superarla y devolver la esperanza de recuperación al resto del mundo.

Una crisis económica que ha puesto de manifiesto la necesidad de afrontar la globalización tal y como hay que hacerlo: es decir, de una forma global, de una forma en la que se sienta concernida, no una pequeña parte, sino toda la ciudadanía del mundo. Las resistencias en este proceso van a ser — nunca mejor dichopoderosísimas pero hay que empezar ya. Habrá que tranquilizar con mucho tacto y prudencia a los países poderosos. Habrá que concederles derechos (incluido el de veto) y privilegios especiales durante un cierto tiempo que puede ser largo. Pero solo así se irán educando, y nos iremos educando todos, en esta nueva idea de una globalización auténtica.

\section{CONCLUSIÓN}

El mundo jurídico — que no podrá contar en esta tarea con la colaboración del mundo político- tiene que comprometerse a fondo en la tarea de diseñar las estructuras adecuadas de unas instituciones decisivas para un futuro digno y civilizado. Habrá que concentrarse con prioridad en unas nuevas Naciones Unidas que es oficio pendiente desde hace muchas décadas; en una Corte Penal Internacional que tenga auténtica capacidad de acción; en una institución global financiera que supere las limitaciones y las inmensas burocracias del Banco Mundial y el Fondo Monetario Internacional y que luche a fondo contra la corrupción y los paraísos fiscales; y, por último, en otra institución global —nadie puede dudar de su absoluta necesidad — para la protección del medio ambiente. Y luego todo lo demás, incluyendo la idea de un derecho global que merece y tendrá capítulo aparte.

Ese es el reto. Un maravilloso reto. Un reto, por fin, asumible. 